\title{
Efeito da Época de Aplicação e Dosagem do Acibenzolar- S-Metil na Indução de Resistência à Murcha-de-Verticillium em Cacaueiro*
}

\author{
Leonardo S. Cavalcanti \& Mário Lúcio V. Resende \\ Departamento de Fitopatologia, Universidade Federal de Lavras, Cx. Postal 37, CEP 37200-000, \\ Lavras, MG, e-mail: mlucio@ufla.br
}

(Aceito para publicação em 28/07/2004)

Autor para correspondência: Mário Lúcio Vilela de Resende

CAVALCANTI, L.S. \& RESENDE, M.L.V. Efeito da época de aplicação e dosagem do acibenzolar-S-metil na indução de resistência à murcha-de-Verticillium em cacaueiro. Fitopatologia Brasileira 29:67-71. 2004.

\section{RESUMO}

A resistência induzida representa uma medida promissora no manejo de doenças como a murcha-de-Verticillium do cacaueiro (Theobroma cacao), visto que possibilita a exploração de cultivares com boas características agronômicas, porém apresentando suscetibilidade a doenças. Grande avanço nessa área ocorreu com a utilização do éster S-metil do ácido benzo-(12-3)-tiadiazole-7-carbotióico (acibenzolar-S-metil, ASM). Contudo, a eficiência desse composto é função, principalmente, da época de aplicação e dosagem utilizada. O presente trabalho teve como objetivo identificar a melhor época de aplicação e dosagem do ASM na interação cacaueiro x Verticillium dahliae. O ASM foi pulverizado via foliar nas concentrações de 20 ou 60 g do ingrediente ativo (i. a.)/100 1 de água, em plântulas de cacaueiro cv Theobahia, aos 15, sete ou três dias antes da inoculação do patógeno. Foram avaliadas as variáveis índice de doença, aos 30, 45 e 60 dias após a inoculação de V. dahliae, a área abaixo da curva de progresso da doença (AACPD), e o peso fresco e altura das plantas aos 60 dias após a referida inoculação. O fator época de aplicação apresentou influência predominante ao fator dosagem, sendo identificada a época referente a 15 dias antes da inoculação como melhor época de aplicação do ASM. Reduções de até 55,4\% na severidade da doença e um acréscimo na ordem de $10,5 \%$ no peso fresco e $35,7 \%$ na altura das plantas foram observadas, quando da utilização da dosagem de $20 \mathrm{~g}$ do i.a./100 1 de água, em comparação com as plantas somente inoculadas com o fungo, evidenciando a eficácia do ASM como indutor de resistência em plântulas de cacaueiro suscetíveis à murcha-de-Verticillium.

Palavras-chave adicionais: Verticillium dahliae, Theobroma cacao, resistência induzida, BTH.

\begin{abstract}
Effect of time and dosage of acibenzolar-S-methyl applications in inducing resistance to Verticillium wilt in cocoa seedlings

Induced resistance represents a promissing strategy in the integrated management of Verticillium wilt of cocoa (Theobroma cacao), because it makes it possible to exploit susceptible cultivars with good agronomical characteristics. Great advances in this area have occurred with the use of the S-methyl ester of benzo-(1,2,3)-thiadiazol-7-carbotioic acid (acibenzolar-S-methyl, ASM). However, the efficiency of this compound depends on the time of application and dosage used. The purpose of this study was to identify the best time of application and correct dosage of ASM in the pathosystem cocoa $\mathrm{x}$ Verticillium dahliae. The ASM was sprayed onto the leaves of cocoa seedlings cv Theobahia, at $20 \mathrm{~g}$ or $60 \mathrm{~g}$ of active ingredient (a. i.)/100 1 of water, 15, seven or three days before pathogen inoculation. The disease index at 30, 45 and 60 days after pathogen inoculation was evalueted using the area under the disease progress curve (AUDPC), and the fresh weight and height of seedlings 60 days after inoculation. The time of application had a more important influence than dosage; 15 days before inoculation was found to be the best time for application of ASM. Decreases of up to $55.4 \%$ in the disease index, increases of $10.5 \%$ in fresh weight and $35.7 \%$ in plant height were observed at a dose of $20 \mathrm{~g}$ a. i./ 1001 of water, when compared to control seedlings inoculated with only the pathogen, thus evidencing the efficacy of ASM as a resistance inducer in cocoa seedlings susceptible to Verticillium wilt.
\end{abstract}

Palavras-chave adicionais: Verticillium dahliae, Theobroma cacao, induced resistance, BTH.

Atualmente a indução de resistência vem sendo alvo de diversos estudos nos mais variados patossistemas vegetais. Tais estudos vislumbram a utilização da mesma como uma

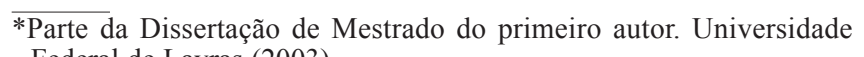
Federal de Lavras (2003) medida de controle de doenças, que pode, juntamente com outras, tradicionalmente utilizadas, compor um adequado manejo, focalizando a redução de custos e perdas ocasionadas.

Agentes bióticos, como organismos não-patogênicos ou atenuados, e abióticos, como quitosana, ácido salicílico, 


\section{L.S. Cavalcanti \& M.L.V. Resende}

ácido di-cloro isonicotínico e ácido $\beta$-amino butírico, têm sido utilizados na indução de respostas de defesa em diversas espécies vegetais, contra infecções virais, fúngicas e bacterianas (Lawton et al., 1996).

Dentre os produtos sintéticos, uma molécula utilizada atualmente é o éster S-metil do ácido benzo-(1,2,3)-tiadiazole7-carbotióico (ASM), que têm apresentado proteção expressiva contra patógenos em diversos hospedeiros (Gorlach et al., 1996; Friedrich et al.,1996; Lawton et al., 1996; Benhamou e Bélanger, 1998 a;b; Morris et al., 1998; Hijwegen \& Termorshuizen, 2000). No Brasil, esta molécula já está registrada comercialmente como indutor de resistência, embora ainda esteja em fase de testes, apresentando resultados significativos em algumas culturas como tomateiro (Lycopersicon esculentum Mill.) (Silva et al. 2000), sorgo [Sorghum bicolor (L.) Moench] (Osswald et al., 1998), citros (Citrus spp.) (Pascholati, 1999) e cacaueiro (Theobroma cacao L.) (Resende et al., 2000).

Em cacaueiro, a utilização da resistência induzida possibilitou a redução da incidência da principal doença da cultura no Brasil, a vassoura-de-bruxa, causada por Crinipellis perniciosa (Stahel) Singer, apresentando resultados superiores àqueles obtidos com o uso de fungicidas tradicionalmente utilizados no controle desta doença (Resende et al., 2000).

A murcha-de-Verticillium, causada por Verticillium dahliae Kleb., é uma importante doença vascular, que representa um sério fator limitante à produção em algumas das principais regiões produtoras da Bahia e Espírito Santo, principalmente em condições de deficiência hídrica (Almeida et al., 1993). O controle químico dessa doença vascular é economicamente inviável e o número de materiais apresentando um nível de resistência satisfatório é reduzido (Resende, 1994; Luz et al., 1997).

A falta de conhecimentos sobre a melhor época de aplicação e dosagem induz a resultados não conclusivos sobre a eficiência e possibilidade de uso desse produto, uma vez que, cada interação patógeno-hospedeiro deve possuir um período próprio, necessário para a sinalização e a conseqüente ativação de genes de defesa da planta, relacionados à resistência sistêmica adquirida (Uknes et al., 1996). Assim sendo, faz-se necessário a realização de estudos detalhados para a identificação das melhores época de aplicação e dosagem do ASM, viabilizando a utilização da indução de resistência como um moderno componente em um programa de manejo racional de doenças do cacaueiro.

O objetivo do presente trabalho foi identificar a melhor época de aplicação e dosagem do acibenzolar-S-metil na indução de resistência em plântulas de cacaueiro à murcha-deVerticillium.

As plântulas foram obtidas a partir de sementes de cacau cv. Theobahia, pré-germinadas em vermiculita e semeadas em sacos de polietileno contendo substrato à base de areia, esterco e solo, na proporção 1:1:1, sendo adubadas aos 30 e 60 dias após a germinação, com adubo NPK, na fórmula 4-14-8, e irrigadas diariamente. As mesmas foram mantidas em estufa climatizada, até o momento da instalação do experimento, com cerca de 90 dias após germinadas, quando foram levadas à casa de vegetação, com uma temperatura média de $25{ }^{\circ} \mathrm{C}$ e umidade relativa variando entre 50 e $80 \%$, sendo dispostas em bancadas de aço, conforme o delineamento utilizado.

A fim de evitar a queima de folhas, devido à ação do vento gerado artificialmente e de luz intensa, o que poderia vir a mascarar os sintomas de murcha e queda de folhas, foram fixadas uma proteção plástica lateral e uma cobertura escura a $1,0 \mathrm{~m}$ das plataformas das bancadas, sendo as mesmas mantidas até o final do experimento.

$\mathrm{O}$ produto comercial à base de acibenzolar-S-metil (Bion (®) foi aplicado aos 15 , sete e três dias antes da inoculação do patógeno, via pulverização foliar, sendo testadas duas dosagens: 1) $20 \mathrm{~g}$ do i.a./100 le 2) $60 \mathrm{~g}$ do i.a./100 1 de água. As plantas do tratamento controle absoluto e aquelas inoculadas com o patógeno, porém sem aplicação do ASM, foram separadas das demais, apenas retornando ao local do experimento $24 \mathrm{~h}$ mais tarde, evitando assim o contato com o produto ocasionado por deriva no momento da aplicação. No tratamento apenas pulverizado com ASM, utilizou-se a dosagem de $20 \mathrm{~g}$ de i.a./100 1 de água.

$O$ isolado de $V$. dahliae, obtido de plantas de morangueiro (Fragaria sp.), provenientes do município de Venda Nova, ES, foi cultivado em meio de cultura BDA, durante 25 dias, em câmara de crescimento, a uma temperatura em torno de $25^{\circ} \mathrm{C}$, em regime de $12 \mathrm{~h}$ claro (iluminação fluorescente) / escuro. Em seguida, transferiu-se disco de meio de cultura colonizado para placa de Petri contendo BDA. O inóculo foi preparado a partir de colônias com 25 dias de incubação, adicionando-se $20 \mathrm{ml}$ de água destilada em cada placa e efetuando-se a raspagem da colônia com escova de cerdas macias. A suspensão foi filtrada em camada dupla de gaze, sendo a concentração ajustada para $1 \times 10^{7}$ conídios viáveis $/ \mathrm{ml}$ de água, em câmara de Neubauer.

A inoculação foi realizada através do método de punção na haste, conforme descrito por Bugbee \& Presley (1967), com seringa plástica e agulha estéreis. A agulha foi inserida em um ângulo de $45^{\circ}$ com o caule, até atingir o lenho da planta, o que é facilmente percebido pela maior resistência à penetração da agulha. Uma única gota da suspensão de inóculo (cerca de 10 $\mu 1)$ teve acesso ao córtex, onde foi rapidamente absorvida. As plantas testemunhas foram, de maneira similar, injetadas com água destilada esterilizada.

As avaliações foram realizadas aos 30, 45 e 60 dias após a inoculação, através da determinação da severidade da doença, utilizando-se uma escala de notas preconizada por Sidhu \& Webster (1977), com notas variando de 0 a 4 , onde as notas 0 , $1,2,3$ e 4 correspondem respectivamente a $0 \%, 1-25 \%, 26-50 \%$, $51-75 \%$ e $>75 \%$ de redução de área foliar, devido a clorose, necrose e murcha. A partir desses dados, foi calculado o índice de doença, baseado na seguinte fórmula:

Índice de doença $=\frac{\text { Soma das notas das folhas por planta }}{\text { Número total de folhas por planta }}$

O peso fresco da parte aérea e a altura das plantas foram quantificados 60 dias após a inoculação com $V$. dahliae. Além dessas variáveis, foi realizada a análise da área abaixo da 
Efeito da época de aplicação e dosagem do acibenzolar-S-metil...

curva de progresso da doença (AACPD), utilizando-se os valores das três avaliações do índice de doença.

$\mathrm{O}$ experimento foi delineado em blocos casualizados, com seis tratamentos originários de arranjo fatorial 3 (épocas de aplicação) x 2 (dosagens), somados a três tratamentos adicionais, formados pelas plantas controle, somente inoculadas com $V$. dahliae $\left(\mathrm{T}_{V d}\right.$ ), pulverizadas com ASM e não inoculadas $\left(\mathrm{T}_{\mathrm{ASM}}\right)$ e sem qualquer inoculação ou pulverização $\left(\mathrm{T}_{\mathrm{ABS}}\right)$. Cada tratamento foi constituído por quatro repetições, sendo as mesmas formadas por nove plantas. As análises de variância e de regressão foram realizadas com auxílio do software estatístico SAS (SAS Institute, 1997).

Através da análise da curva de progresso da doença (Figura 1) e da AACPD (Tabela 1), confirmou-se o melhor desempenho das plantas pulverizadas com ASM 15 dias antes da inoculação desafiadora, principalmente na dosagem de $20 \mathrm{~g}$ i.a./100 1 de água, em relação aos demais tratamentos.

Evidenciou-se assim, a influência da época de aplicação do ASM, sobrepondo-se ao efeito da dosagem utilizada, o que confirma a estrita necessidade de um período entre a aplicação indutora e a inoculação do patógeno (Uknes et al., 1996). Apesar do número reduzido de estudos relacionados com a indução de respostas de defesa em plantas com estrutura semelhante à do cacaueiro, o período entre a aplicação indutora e a desafiadora difere significativamente daquele observado em plantas herbáceas como tomateiro e pepino (Cucumis sativus L.), que apresentam respostas de defesas efetivas ativadas em um curto espaço de tempo (três a sete dias), quando induzidas pela aplicação de químicos ou através da pré-inoculação com não patógenos (Benhamou e Bélanger, 1998 a; b).

Em cacaueiro, esse período parece compreender um espaço de tempo mais longo, como relatado por Resende et al. (2000), em plantas que apresentaram resistência induzida contra C. perniciosa. Nesse estudo, os autores obtiveram uma maior redução na incidência de vassoura-de- bruxa nas plantas pulverizadas com o ASM aos 30 dias antes da inoculação do patógeno, sendo os resultados desse tratamento superiores àqueles obtidos com a aplicação do ASM aos três e 15 dias antes da inoculação.

Embora o fator época de aplicação tenha apresentado uma maior influência sobre os valores da variável índice de doença, na primeira e segunda avaliações, o fator dosagem pode ter sido determinante da severidade da doença na terceira avaliação da variável índice de doença. Nessa avaliação, nos tratamentos cuja aplicação do ASM foi realizada aos 15 dias antes da inoculação, verificou-se uma relação direta entre o aumento da dosagem do produto e a elevação dos valores desta variável.

A maior severidade da doença observada concomitante ao aumento da dosagem do ASM pode ser devido à aproximação das doses estimadas dos valores limites, ou seja, de valores máximos onde a partir desses, a eficiência do produto na indução de respostas de defesa é reduzida de maneira significativa. Na interação entre sorgo e Colletotrichum graminicola (Ces.) Wils., Osswald et al. (1998), verificaram uma relação direta entre o aumento da dosagem do ASM e a
TABELA 1 - Valores da área abaixo da curva de progresso da doença (AACPD), nos diferentes tratamentos, com base nas três avaliações da variável índice de doença

\begin{tabular}{lcll}
\hline \hline \multicolumn{2}{c}{ TRATAMENTO* } & \multirow{2}{*}{ AACPD } \\
\cline { 1 - 2 } Dosagem & Época & & \\
\hline 20 & 15 & 59,96 & $\mathrm{~b}$ \\
20 & 07 & 77,14 & $\mathrm{~b}$ \\
20 & 03 & 63,16 & $\mathrm{bc}$ \\
60 & 15 & 56,32 & $\mathrm{bc}$ \\
60 & 07 & $58,16 \mathrm{~b}$ \\
60 & 03 & $66,95 \mathrm{bc}$ \\
$\mathrm{T}_{V d}$ & & $8,88 \mathrm{a}$ \\
$\mathrm{T}_{\mathrm{ASM}}(20$ g do i.a./ 100 1 de água) & $2,66 \mathrm{a}$ \\
$\mathrm{T}_{\mathrm{ABS}}$ & & \\
\hline
\end{tabular}

*Tratamentos com letras iguais não diferem estatisticamente a $5 \%$ de probabilidade; C.V. $=23,77 \%$.
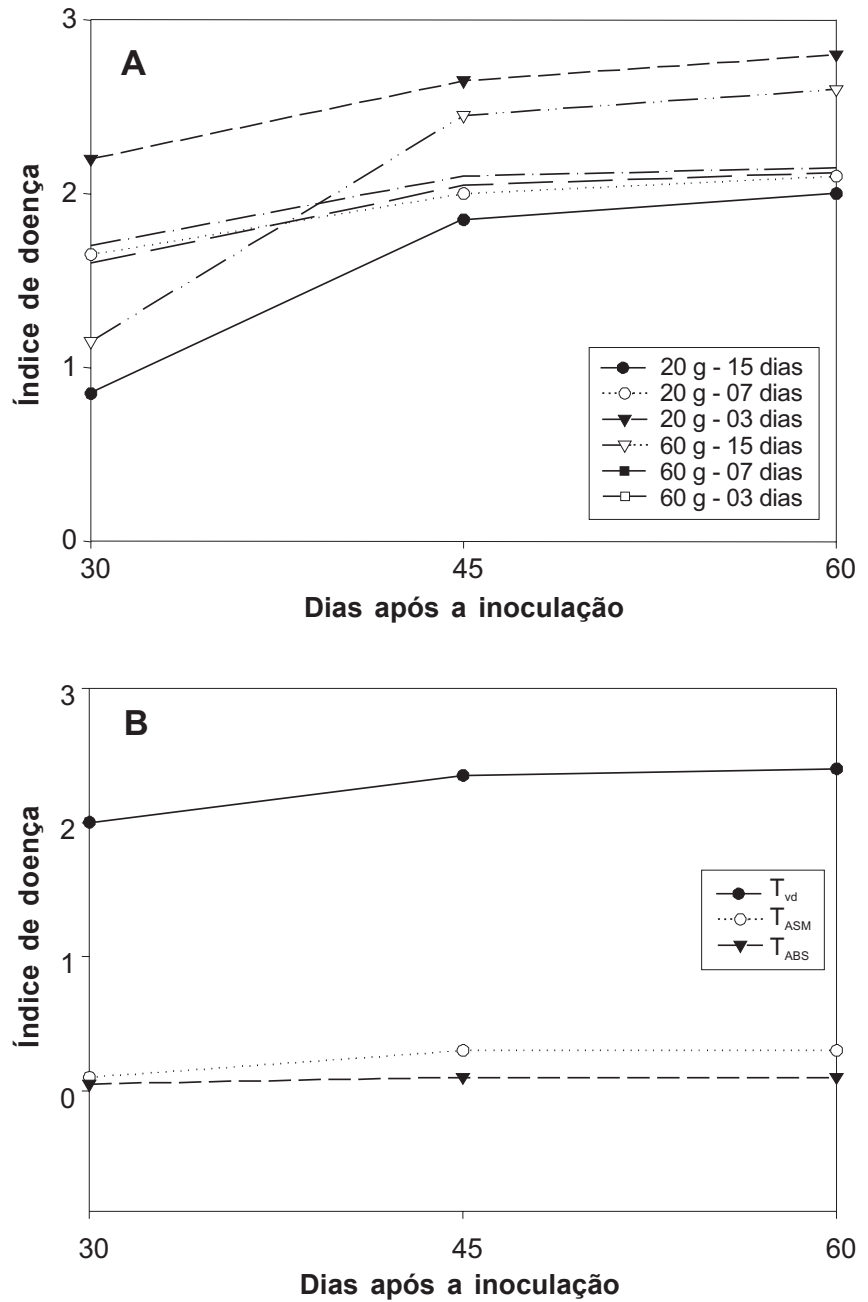

FIG. 1 - Curva de progresso da murcha de Verticillium em plântulas de cacaueiro (Theobroma cacao) em diferentes dosagens e tempo de aplicação do ASM antes da inoculação (A); e nas respectivas testemunhas (B). $\mathrm{T}_{\mathrm{Vd}}=$ testemunha inoculada; $\mathrm{T}_{\mathrm{ASM}}=$ testemunha somente pulverizada com ASM; $\mathrm{T}_{\mathrm{ABS}}=$ testemunha sem inoculação e sem aplicação de ASM. 
produção de fitoalexinas nos tecidos de mesocótilos, sendo que nessa interação o possível valor limite está em torno de 50 ppm do ASM (Pascholati, 1999).

Não foram observadas diferenças estatisticamente significativas, a 5\% de probabilidade, pelo teste de Duncan, entre os valores da variável peso fresco da parte aérea das plantas nos tratamentos onde o ASM foi aplicado aos 15 antes da inoculação do patógeno, em relação ao peso fresco das plantas somente inoculadas com $V$. dahliae (Figura 2A).

Para a variável altura das plantas, observou-se significativa influência do fator época de aplicação, de maneira independente do fator dosagem, ocorrendo uma superioridade do tratamento onde o ASM foi pulverizado aos 15 dias antes da inoculação desafiadora. Quando comparadas com altura das plantas do controle positivo, percebeu-se um aumento, na ordem de 35,7\%, na altura das plantas desses tratamentos (Figura 2B). Pela análise de regressão linear, verificou-se que os valores de altura obtidos apresentaram-se diretamente proporcionais ao período entre a aplicação de ASM e a inoculação do patógeno (Figura 3).

Os valores referentes às variáveis peso fresco e altura das plantas (Figuras 2A e B) que apenas receberam a aplicação foliar do ASM, sem posterior inoculação do patógeno $\left(\mathrm{T}_{\mathrm{ASM}}\right)$,
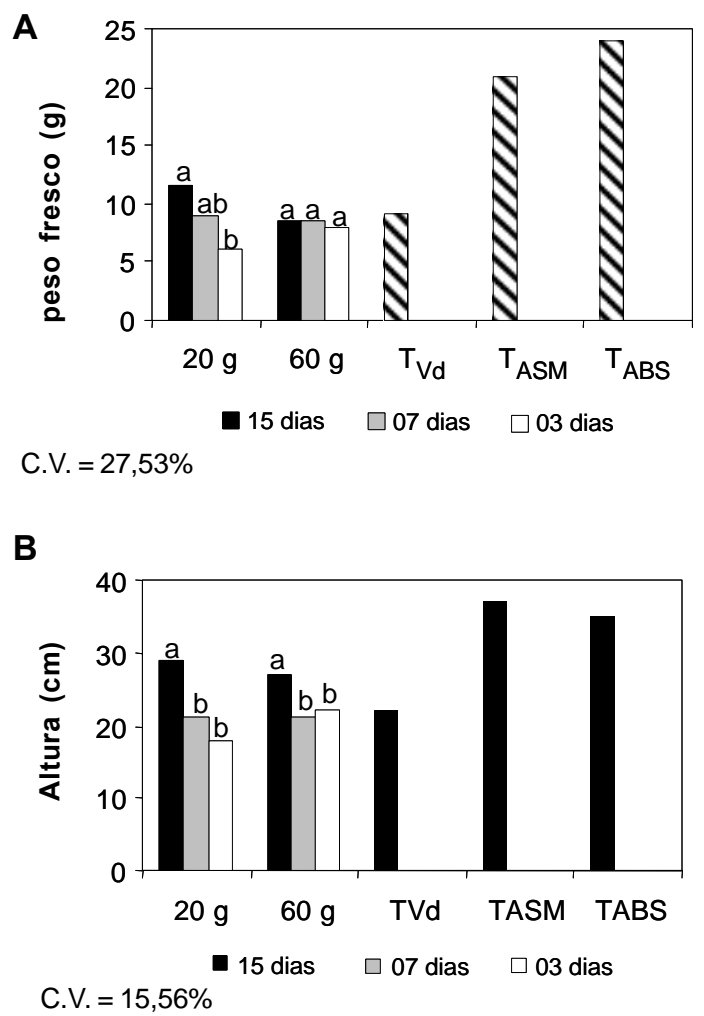

FIG. 2 - Valores das variáveis peso fresco (A) e altura (B) de plântulas de cacaueiro (Theobroma cacao), 60 dias após a inoculação com Verticillium dahliae, nos diferentes tratamentos. $\mathrm{T}_{\mathrm{Vd}}=$ testemunha inoculada; $\mathrm{T}_{\mathrm{ASM}}=$ testemunha somente pulverizada com $\mathrm{ASM} ; \mathrm{T}_{\mathrm{ABS}}=$ testemunha sem inoculação e sem aplicação de ASM. Tratamentos com letras iguais dentro da dosagem não diferem estatisticamente a $5 \%$ de probabilidade. apresentaram-se muito próximos aqueles verificados nas plantas controle absolutas $\left(\mathrm{T}_{\mathrm{ABS}}\right)$, sem qualquer tipo de tratamento. Isso sugere ausência de fitotoxicidade do ASM, ou de qualquer tipo de efeito negativo no desenvolvimento das plântulas de cacaueiro, nas concentrações utilizadas nesse estudo.

A análise de tais resultados leva à indicação que a utilização do acibenzolar-S-metil na indução de respostas de defesa pode ser estendida a outros patossistemas. Em cacaueiro, esta ferramenta pode representar uma alternativa eficiente na busca de medidas de manejo integrado de importantes doenças, como a vassoura-de-bruxa e a murchade-Verticillium, responsáveis por elevada redução na produtividade desta cultura. Contudo, faz-se necessária a realização de estudos similares com plantas adultas no campo, uma vez que o presente estudo foi realizado com plântulas em casa de vegetação.

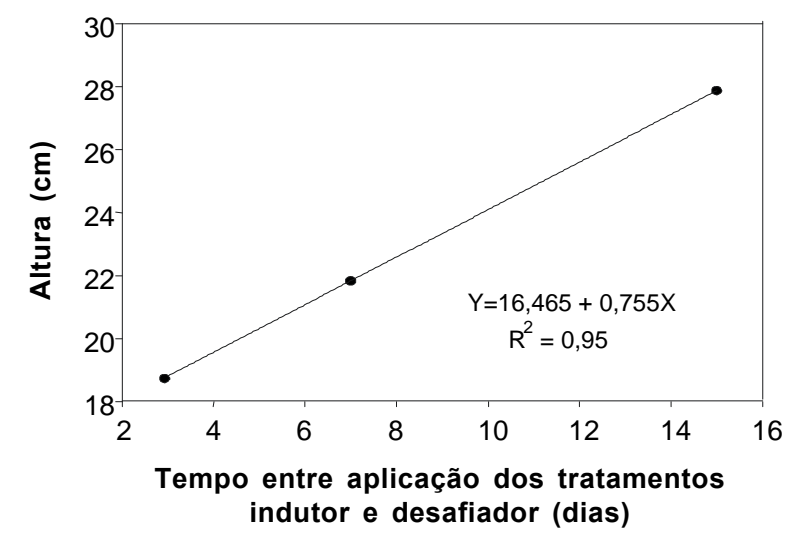

FIG. 3 - Regressão linear da variável altura das plântulas de cacaueiro (Theobroma cacao) aos 60 dias após a inoculação com Verticillium dahliae.

\section{REFERÊNCIAS BIBLIOGRÁFICAS}

ALMEIDA, H.A., ALMEIDA, L.C.C. \& LIMA, A.A. Efeito da deficiência hídrica sobre o surgimento da murcha de Verticillium no cacaueiro. Anais, $8^{\circ}$ Congresso Brasileiro de Agrometeorologia, Santa Maria, RS. 1993. p. 187.

BENHAMOU, N. \& BÉLANGER, R.R. Induction of systemic resistance to Pythium damping-off in cucumber plants by benzothiadiazole:ultrastructure and cytochemistry of the host response. Plant Journal 14:13-21. 1998a.

BENHAMOU, N. \& BÉLANGER, R.R. Benzothiadiazolemediated induced resistance to Fusarium oxysporum f. sp. radicislycopersici in tomato. Plant Physiology 118:1203-1212. 1998b.

BUGBEE, W.M. \& PRESLEY, T.J. A rapid inoculation technique to evaluate the resistance of cotton to Verticillium albo-atrum. Phytopathology 57:1264. 1967.

FRIEDRICH, L., LAWTON, K., RUESS, W., MASNER, P., SPECKER, N., GUT RELLA, M., MEIER, B., DINCHER, S., STAUB, T., UKNESS, S. \& RYALS, J. A benzothiadiazole derivate induces systemic acquired resistance in tobacco. Plant Journal 10:6170. 1996. 
GÖRLACH, J., VOLRATH, S., KNAUFF-BEITER, G., HENGY, G., BECKHOVE, U., KOGEL, K. H., OOSTENDORP, M., STAUB, T., WARD, E., KESSMANN, H. \& RYALS, J. Benzothiadiazole, a novel class of inducers of systemic acquired resistance, activates gene expression and disease resistance in wheat. Plant Cell 8:629-643. 1996.

HIJWEGEN, T. \& TERMORSHUIZEN, A.J. Retarded development of Verticillium wilt in eggplant after application of Bion or Oryzalin. Zeitschrift für Pflanzenkrankeiten und Pflanzenschutz 107:267-273. 2000.

LAWTON, K.A., FRIEDRICH, L., HUNT, M., WEYMANN, K., DELANEY, T., KESSMANN, H., STAUB, T. \& RYALS, J. Benzothiadiazole induces disease resistance in Arabidopsis by activation of the systemic acquired resistance signal transduction pathway. Plant Journal 10:71-82. 1996.

LUZ, E.D.M.N., BEZERRA, J.L., RESENDE, M.L.V. \& OLIVEIRA, M.L. Cacau (Theobroma cacao L.): Controle de doenças. In: Vale, F.X.R. \& Zambolim, L. (Eds.). Controle de Doenças de Plantas. v. 2. Viçosa. UFV.1997. pp.611-655.

MORRIS, S.W., VERNOOIJ, B., TITATARN, S., STARRET, M., THOMAS, S., WILTSE, C.C., FREDERIKSEN, R.A., BRANDHUFALCK, A., HULBERT, S. \& UKNES, S. Induced resistance responses in maize. Molecular Plant-Microbe Interactions 11:643-658. 1998.

OSSWALD, W., PASCHOLATI, S.F., STANGARLIN, J.R., LEME, LC.D.T. \& WULFF, N.A. Acúmulo de fitoalexinas em mesocótilos de sorgo em resposta ao tratamento com o ativador de defesa vegetal 'Bion'. Fitopatologia Brasileira 23:266. 1998. (Resumo).

PASCHOLATI, S.F. (Coord.). Conclusões do grupo de discussão
Bioquímica fitopatológica e indução de resistência. Fitopatologia Brasileira 24:241. 1999. (Resumo)

RESENDE, M.L.V. Vascular wilt of cocoa (Theobroma cacao L.), caused by Verticillium dahliae Kleb.:studies on pathogenicity and resistance. (Ph.D. Thesis). Bath, U.K. University of Bath. 1994.

RESENDE, M.L.V., NOJOSA, G.B.A., AGUILAR, M.A.G., SILVA, L.H.C.P., NIELLA, G.R., CARVALHO, G.A., GIOVANINI, G.R. \& CASTRO, R.M. Perspectivas da indução de resistência em cacaueiro contra Crinipellis perniciosa, através do benzotiadiazole (BTH). Fitopatologia Brasileira 25:153-162. 2000.

SAS INSTITUTE. SAS/STAT Software:changes and enhancements through release 6.12. Cary, NY. 1997.

SIDHU, G.S. \& WEBSTER, J.M. The use of amino acid fungal auxotrophs to study the predisposition phenomena in the rootknot: wilt fungus disease complex. Physiological Plant Pathology 11:117-127. 1977.

SILVA, L.H.C.P., RESENDE, M.L.V., MARTINS JÚNIOR, H., CAMPOS, J.R., SOUZA, R.M. \& CASTRO, R.M. Época e modo de aplicação do ativador de plantas benzotiadiazole (BTH) para a proteção contra a mancha bacteriana. Horticultura Brasileira 18:375376. 2000.

UKNES. S., VERNOIJ, B., MORRIS, S., CHANDLER, D., STEINER, H., SPECKER, N., HUNT, M., NEUENSCHWANDER, U., LAWTON, K., STARRET, M., FRIEDRICH, L., WEIMANN, K., NEGROTTO, D., GÖRLACH, J., LANAHAN, M., SALMERON, J., WARD, E., KESSMANN, H \& RYALS, J. Reduction of risk for growers:methods for the development of disease-resistance crops. New Phytologist 133:3-10. 1996. 